This is the author's final, peer-reviewed manuscript as accepted for publication. The publisher-formatted version may be available through the publisher's web site or your institution's library.

\title{
Thermal properties of big bluestem as affected by ecotype and planting location along the precipitation gradient of the Great Plains
}

Ke Zhang, Loretta Johnson, Richard Nelson, Wenqiao Yuan, Zhijian Pei, Xiuzhi S. Sun, Donghai Wang

\section{How to cite this manuscript}

If you make reference to this version of the manuscript, use the following information:

Zhang, K., Johnson, L., Nelson, R., Yuan, W., Pei, Z., Sun, X. S., \& Wang, D. (2014). Thermal properties of big bluestem as affected by ecotype and planting location along the precipitation gradient of the Great Plains. Retrieved from http://krex.ksu.edu

\section{Published Version Information}

Citation: Zhang, K., Johnson, L., Nelson, R., Yuan, W., Pei, Z., Sun, X. S., \& Wang, D. (2014). Thermal properties of big bluestem as affected by ecotype and planting location along the precipitation gradient of the Great Plains. Energy, 64, 164-171.

Copyright: (@) 2014 Elsevier Ltd.

Digital Object Identifier (DOI): 10.1016/j.energy.2013.11.071

Publisher's Link: http://dx.doi.org/10.1016/i.energy.2013.11.071

This item was retrieved from the K-State Research Exchange (K-REx), the institutional repository of Kansas State University. K-REx is available at http://krex.ksu.edu 
Thermal properties of big bluestem as affected by ecotype and planting location along the precipitation gradient of the Great Plains

Ke Zhang, ${ }^{\dagger}$ Loretta Johnson, ${ }^{\ddagger}$ Richard Nelson, ${ }^{\S}$ Wenqiao Yuan, ${ }^{*}$ Zhijian Pei, ${ }^{,}$Xiuzhi S. Sun, ${ }^{\ddagger}$ and Donghai Wang*,

${ }^{\dagger}$ Department of Biological and Agricultural Engineering, Kansas State University, Manhattan, KS 66506

${ }^{\star}$ Department of Biology, Kansas State University, Manhattan, KS 66506

${ }^{\S}$ Center for Sustainable Energy, Kansas State University, Manhattan, KS 66506

${ }^{*}$ Department of Biological and Agricultural Engineering, North Carolina State University, Raleigh, NC, 27695

"Department of Industrial and Manufacturing System Engineering, Kansas State University, Manhattan, KS 66506

${ }^{*}$ Department of Grain Science and Industry, Kansas State University, Manhattan, KS 66506

*Corresponding author. Telephone: 785-5322919, Fax: 785-5325825. E-mail: dwang@ ksu.edu. 


\section{Abstract}

The objective of this research was to study the effect of ecotype and planting location on thermal properties of big bluestem. Three big bluestem ecotypes (CKS, EKS, ILL) and a cultivar (KAW) were harvested in 2010 from four locations (Colby, Hays, and Manhattan, KS; and Carbondale, IL) and were evaluated for their specific heat, thermal conductivity, thermal stability, high heating value (HHV), and proximate contents. All populations revealed a large variation in specific heat $(2.35-2.62 \mathrm{~kJ} / \mathrm{kg} / \mathrm{K})$, thermal conductivity $\left(77.85-99.06 \times 10^{-3} \mathrm{~W} / \mathrm{m} / \mathrm{K}\right)$, thermogravimetric analysis as weight loss during the heating process (71-73\%), and HHV $(17.64-18.67 \mathrm{MJ} / \mathrm{kg})$. Specific heat of the big bluestem was significantly affected by planting location, ecotype, and interaction between location and ecotype. Planting location had stronger influence on specific heat than ecotype. Specific heat increased as temperature increased, and a linear correlation model for specific heat prediction was developed as a function of temperature. Ecotype, planting location, and the interaction of ecotype and planting location did not have a significant effect on thermal conductivity; however, density and particle size showed a completely opposite relationship on thermal conductivity. Both planting location and ecotype significantly affected HHV. Among all environmental factors, potential evapotranspiration had the most significant effect on thermal properties.

\section{Introduction}

Renewable energy has received growing attention as people have become more conscious of the fossil fuel shortage and greenhouse gas emissions have been related to global warming [1]. In 2010, renewable energy resources supplied $8 \%$ of the nation's total energy consumption and up to 8.05 quadrillion Btu (increased from 6\% in 2009). Biomass led the other renewable energy 
resources (such as wind, solar, geothermal, and hydroelectric) by contributing 53\% of the nation's renewable energy supply in 2010 [1]. Biomass resources include various natural and derived materials, such as woody and herbaceous species, wood wastes, bagasse, agricultural and industrial residues, waste paper, municipal solid waste, sawdust, biosolids, grass, waste from food processing, animal wastes, aquatic plants, algae, etc. [2]. Big bluestem (Andropogon gerardii) is regarded as second-generation biomass and recently has been proposed as promising energy crops because their growth requires few agricultural inputs (fertilizer and pesticides). Propheter and Staggenborg reported that only one tenth of nitrogen filterlizers were required for big bluestem during the first two years comparing with annual biofuel crops such as corn, soybean and sorghum [3]. In addition, those annual biofuel crops had much higher soil nitrogen removal rate $\left(160 \mathrm{~kg} \mathrm{ha}^{-1}\right)$ than big bluestem $\left(\sim 30 \mathrm{~kg} \mathrm{ha}^{-1}\right)$ [3]. Lynd reported that perennial grasses such as big bluestem require substantially less fertilizer and pesticides than corn as biofuel feedstocks [4]. In the United States, big bluestem dominates the tallgrass prairie of North America and is a major component of prairie biomass [5, 6]. Moreover, tolerance to heat and drought have enabled big bluestem to fill the deficiency in grasslands in the Midwestern U.S. when cool-season grasses (C3) are unproductive [7-9]. Recently Nature article reported that successional herbaceous vegetation, such as big bluestem and alfalfa, on marginal lands in tem Midwestern U.S. states can not only provide greenhouse gas emissions mitigation, but also produce substantial proportion of future biofuel energy target [10].

Thermal, biological, and physical processes are the three major technologies that help make use of a wide variety of biomass. In thermal conversion technologies, direct combustion and cofiring with coal were first utilized for electricity production and once were responsible for over 97\% of the world's bio-energy production [11]. Pyrolysis has attracted the highest interest 
because it produces bio-oil, which can be used as a fuel in stable engines and converted into chemicals such as bio-lime nitrogen fertilizer [12]. Biomass gasification has been researched extensively due to its higher efficiencies compared with combustion, and fast pyrolysis is still at a relatively early stage of development [13]. Torrefaction, another promising thermal process, improves the quality of biomass in terms of heat content, physical properties, and chemical composition for combustion and gasification applications [14].

Understanding, predicting, and controlling these thermal processes and designing processing equipment require knowledge of the thermal properties of biomass, such as specific heat, thermal conductivity, thermal stability, high heating value, and proximate contents.

Specific heat of a substance $(\mathrm{kJ} / \mathrm{kg} / \mathrm{K})$ is defined as the amount of heat required to increase the temperature of a unit of mass by one degree. Specific heat affects the total energy required for thermal conversion of biomass into biofuels. The specific heat of biomasses depends largely on their composition; using the specific heat of each component of a mixture and the mass fraction is usually sufficient to predict the specific heat of the mixture [15]. Although the method based on the specific heat of the components in the mixture is most widely used to predict specific heat because of its simplicity, experimentally determined value is usually higher than predicted value [16]. Koch utilized differential scanning calorimetry (DSC) as a convenient technique for measuring the specific heat of wood and bark of 72 spruce pine trees [17].

Thermal conductivity of a material $(\mathrm{W} / \mathrm{m} \mathrm{K})$ is a measure of its ability to conduct heat. Thermal conductivity of biomass depends mostly on composition and the characteristics of the biomass that affect the heat flow paths through the material. Mohsenin reviewed thermal conductivity measurement techniques for both steady-state and transient-sate transfers [18]. The heated probe method is simple, fast, and requires only a small sample, and it has been widely 
used for thermal conductivity determination [19]. Thermal stability, the ability of a material to resist changes in physical shape or size as its temperature changes, is essential to understand and predict the reactions and kinetics during biomass thermal conversion. Thermogravimetric analysis (TGA) is the usual technique for determining thermal stability by quantitative measurement of weight changes (loss/gain) associated with thermally induced transition as a function of temperature or time [20]. High heating value $(\mathrm{MJ} / \mathrm{kg})$ is an important thermal parameter to characterize the amount of energy produced by the combustion of a unit mass of a material. Proximate analysis is a simple and rapid procedure for defining the substance energy content and determining how clean and efficient the substance is for the purpose.

Our recent research on big bluestem showed that planting location and ecotype as well as interaction of planting location and ecotype had significant effects on chemical and elemental composition of big bluestem [21]. In addition, our study also showed that bio-oil yield from big bluestem through hydrothermal conversion was significantly affected by both ecotype and planting location [22]. However, we found no research on the thermal properties of big bluestem, especially the effects of ecotype and planting location on the thermal properties of big bluestem. Therefore, the objectives of this research were to characterize the thermal properties of big bluestem and to study the effects of ecotype and planting location on thermal properties of big bluestem and thus, fill a critical gap in fundamental knowledge of thermal properties of a valuable bioenergy grass.

\section{MATERIALS AND METHODS}

\subsection{Materials}


Three big bluestem ecotypes, CKS (Cedar Bluffs [CDB]), EKS (Konza [KON]), and ILL (12Mile [12M]), and the KAW cultivar, which is widely planted to restore marginal lands, were harvested from reciprocal garden plots in four planting locations (Colby, Hays, and Manhattan, KS; and Carbondale, IL) in 2010. Among the four locations, the Colby planting site was used to test the threshold of drought tolerance and the possibility for planting in drier Great Plains locations. Two populations from each ecotype were evaluated for thermal properties. No nitrogen fertilizers and pesticides were applied to the big bluestem. Details of seed collection and planting location have been described previously [21]. The big bluestem samples were ground into powder using a Retsch SM2000 cutting mill (Haan, Germany) with a 1.0-, 2.0-, and 4.0-mm sieve, respectively. For thermal conductivity measurement, only 2.0- and 4.0-mm particle sizes were used. After grinding, each sample was fully mixed in sealed plastic storage bags. To eliminate any error that might be caused by water, samples were dried at $45{ }^{\circ} \mathrm{C}$ for $24 \mathrm{~h}$ and saved in the plastic bag before measuring specific heat, thermal conductivity, high heating value, and proximate content. All measurements were carried out in short time at room temperature of $22{ }^{\circ} \mathrm{C}$ and $40 \%$ humidity.

\subsection{Specific heat by differential scanning calorimetry (DSC)}

Specific heat of big bluestem was measured with DSC Q200 V24.4 instrument (TA Instruments, New Castle, DE) calibrated with indium and zinc. An empty sealed pan was used as a reference for every measurement. Three-step scans were carried out in this study. The first scan was conducted with an empty hermetic pan to determine the baseline background heat flow, which was subtracted from subsequent measurements. Next, sapphire was weighed and sealed in a pan for determination value of E. E was the calibration constant and calculated by using Equation 1: 
$E=\frac{C_{p s} \times H_{r} \times M}{H \times 60}$

where $C_{p s}$ is specific heat of sapphire, which was standard and obtained from the literature $(\mathrm{kJ} / \mathrm{kg} / \mathrm{K}) ; H_{r}$ is heating rate, which was 10 in this study $(\mathrm{K} / \mathrm{min}) ; M$ is sapphire mass $(\mathrm{mg}) ; H$ is measured heating value ( $\mathrm{mW}$ ); and 60 is conversion constant (min to sec).

For the sample run, an empty pan and a pan with a 5-mg sample were placed into the DSC. The specific heat of the sample is calculated by transposition equation and substituting $E$. Largevolume stainless steel pans were used. All measurements were held at $323 \mathrm{~K}$ for $10 \mathrm{~min}$, scanned from $323 \mathrm{~K}$ to $473 \mathrm{~K}$ at a heating rate of $10 \mathrm{~K} / \mathrm{min}$, and then held at $473 \mathrm{~K}$ for another $10 \mathrm{~min}$. The sample was characterized in an inert environment by using nitrogen with a gas flow rate of $50 \mathrm{ml} / \mathrm{min}$.

\subsection{Thermal conductivity by probe method}

Figure 1 shows a diagram of the experimental apparatus for measurement of thermal conductivity using the heated needle probe. The container is filled with biomass with a confined particle size and sample density. The straight needle probe $(60 \mathrm{~mm}$; Thermal logic, Washington, USA) containing a heater wire as heat source and a thermocouple as a temperature-measuring device is inserted at the center of the container. The container's diameter is $30 \mathrm{~mm}$ to ensure measurement time $(3 \mathrm{~min})$ shorter than the time allowing heat transfer to reach the wall of the container. After the initial temperature is equilibrated at room temperature, the heating wire is activated and heated at a constant rate of energy input supplied by a pair of AAA batteries. Then, the temperature rise over time is measured with thermocouple and analyzed by Data Acquisition 
System NI USB-9161(National Instruments). For the mathematical analysis, thermal conductivity can be expressed by Equation 2:

$$
k=\frac{q \ln \left(\frac{t}{t_{0}}\right)}{4 \pi\left(T-T_{0}\right)}
$$

where $k$ and $q$ are the thermal conductivity $(\mathrm{W} / \mathrm{m} / \mathrm{K})$ and heater power dissipated per unit length (W/m), respectively. $T_{0}$ and $t_{0}$ are temperature $(K)$ and time $(s)$ at initial condition. $T$ and $t$ represent temperature $(K)$ and time $(s)$ since the probe heated is energized. The heat power $q$ is calculated using Equation 3:

$$
q=\frac{E_{r e f}^{2}}{R_{r e f}^{2}}\left(R_{m}\right)
$$

where $R m$ is $1041.5 \Omega$ for the probe heater and $E_{r e f}(1 \Omega)$ and $R_{r e f}(0.04 \mathrm{~V})$ are voltage and resistance in the reference resistor, respectively.

\subsection{Thermogravimetric analysis}

The determinations were performed with the Perkin-Elmer Pyris1 thermogravimetric analysis (TGA) instrument (Norwalk, CT) to record the sample mass change with temperature over the course of the paralysis reaction. Initial TGA measurement was carried out at a heating rate of $10{ }^{\circ} \mathrm{C} / \mathrm{min}$ up to $900{ }^{\circ} \mathrm{C}$ to establish the temperature range required for the following investigations. About $8 \mathrm{mg}$ of each sample obtained from a tensile bar was placed in the pan and heated from 30 to $600{ }^{\circ} \mathrm{C}$ at a heating rate of $30{ }^{\circ} \mathrm{C} / \mathrm{min}$ in a nitrogen environment.

\subsection{High heating value}


Gross energy contents were determined by means of a calorimeter (IKA-Calorimeter C 200, IKA-Werke GmbH and Co. KG, Staufen, Germany) with a benzoic acid standard. About $1.00 \mathrm{~g}$ of each pelleted sample was put into an adiabatic bomb and burned to ash. All samples were ground by a miller with a 1.0-mm sieve. Powder samples were compacted into pellets for measurement to reduce error caused by incomplete combustion resulting from dry, loose samples blown away during sudden release of volatiles. In addition, heating value was calculated based on the elemental composition of the biomass sampled.

\subsection{Proximate analysis}

Ash content was determined according to ASTM D-1102-84, "Standard test method for ash in wood" [23]. Volatile matter determination was made in accordance to ASTM E872-82, "Standard test method for volatile matter in the analysis of particulate wood fuels" [24]. Fixed carbon was determined by subtracting the summation of the moisture, volatile matter and ash contents from the total sample mass

\subsection{Statistical analysis}

The reported thermal property values of big bluestem samples are the average of at least two replicates. Data were analyzed with analysis of variance (ANOVA) and Tukey's studentized range (HSD) test in SAS (SAS Institute, Inc., Cary, NC). In general, fully balanced ANOVA tests were performed by following the general linear models (GLM) procedure. Correlations were determined using stepwise multiple regressions and multiple linear regression analysis. In addition to investigating effects of environmental conditions on thermal properties of big bluestem, we performed multiple univariate linear regression analysis. For all weather data, we 
used the National Oceanic and Atmospheric Administration database and historical records dating back to 1961 (see [21] for further details).

\section{Results and discussion}

\subsection{Specific heat}

Figure 2 shows the typical DSC plots of big bluestem, in which heat flow was investigated as a function of temperature. The maximum temperature of DSC measurement was set at $473 \mathrm{~K}$ to prevent explosion of the sealed pan from emissivity of sample pyrolysis. A previous study did not recommend DSC analysis without the lid, although this approach can heat to higher temperature and was more approximate for biomass pyrolysis and gasification [25]. The green curve is the baseline with the sealed pan at a heating rate of $10 \mathrm{~K} / \mathrm{min}$ and was subtracted from following measurements. The red curve and blue curve represent the biomass sample and reference (sapphire) under the same conditions, respectively. The heat flow curve includes the heats evolved during decomposition and reaction of the pyrolysis sample material. Therefore, during an endothermic heat effect, specific heat values increase, whereas specific heat decreases during an exothermic reaction [26]. The heat flow curve of the sample shows a decreased trend after $420 \mathrm{~K}$, although three curves exhibit the positive relationships between heat flow and temperature from $323 \mathrm{~K}$ to $420 \mathrm{~K}$. Because the samples were previously dried to eliminate error from water, this endothermic reaction was associated with decomposition of hemicellulose [27]. Cultivar KAW planted in IL exhibited the most pronounced endothermic peak in this range due to its relatively higher specific heat value and hemicellulose content. The typical relationship between the specific heat and temperature of big bluestem is illustrated in Figure 3. The value of 
specific heat increased linearly from 1.73 to $2.24 \mathrm{~kJ} / \mathrm{kg} / \mathrm{K}$ as temperature increased from $323 \mathrm{~K}$ to $420 \mathrm{~K}$ and followed a second-order polynomial in the whole range. This result suggests that the specific heat of big bluestem increased with heating until the component because to decompose. The average value of the specific heat of big bluestem at $420 \mathrm{~K}$ is $2.46 \mathrm{~kJ} / \mathrm{kg} / \mathrm{K}$ (Table 1), which is in line with the previously reported range of 2.30 to $2.60 \mathrm{~kJ} / \mathrm{kg} / \mathrm{K}$ for wood and grass particle biomasses [28]. Stepwise multiple regression analysis was conducted to relate specific heat to temperature with factors $\mathrm{K}$ and $\mathrm{K}^{2}$. The best equation accounted for $85.1 \%$ of variation with a standard error of the estimate of 0.012 expressed as Equation 4:

Specific heat of big bluestem $=-0.1581 T^{2}+124.64 T-22281$

Equation 4 agreed well with the work of Gupta et al. [29], which indicated that the specific heat of biomass increased by $40 \%$ and basically followed a linear pattern before $430 \mathrm{~K}$ then followed a second-order polynomial for the entire pyrolysis process (Fig 3).

The bars on left side of Figure 4 show the effects of planting location on the specific heat of big bluestem. Big bluestem populations planted in Illinois generally had a higher specific heat at $420 \mathrm{~K}$, with an average of $2.62 \mathrm{~kJ} / \mathrm{kg} / \mathrm{K}$ compared with averages of $2.34 \mathrm{~kJ} / \mathrm{kg} / \mathrm{K}, 2.40 \mathrm{~kJ} / \mathrm{kg} / \mathrm{K}$, and $2.35 \mathrm{~kJ} / \mathrm{kg} / \mathrm{K}$ for populations planted in Colby, Hays, and Manhattan, KS, respectively. The average specific heat of big bluestem planted in Illinois was $0.25 \mathrm{~kJ} / \mathrm{kg} / \mathrm{K}$, which is higher than those from Kansas and indicates that the same big bluestem populations would have around 10.4\% higher value of specific heat if planted in Illinois instead of Kansas. The effect of ecotype on specific heat is shown on right side of Figure 4. CKS, EKS, and ILL ecotypes had statistically similar average specific heat values regardless of planting location, but native cultivar KAW had significantly higher specific heat value than other ecotypes, as indicated by the different letters analyzed by Tukey's HSD test. This result was in agreement with previous studies [21, 22]. 
Table 2 shows that the interaction between planting location and ecotype also had significant effect on specific heat of big bluestem $(p<0.05)$; however, the interaction effect was much less than that of planting location and ecotype and had a smaller $F$-value (11.3). It is noted that the role of the location was always a greater source of variation than ecotype and the interaction between ecotype and location for specific heat value based on larger $F$-value (Table 2 ).

\subsection{Thermal conductivity}

Table 3 summarizes the calculated thermal conductivity of big bluestem at three different densities and particle sizes at 298K. As density increased from 300 to $360 \mathrm{~kg} / \mathrm{m}^{3}$, the value of thermal conductivity of big bluestem with particle sizes of $1 \mathrm{~mm}, 2 \mathrm{~mm}$, and $3 \mathrm{~mm}$ increased by 32, 44, and 49\%, respectively. This result is probably explained by the fact that compression decreases the proportion of air held in samples, and air has lower thermal conductivity $\left(24 \times 10^{-3}\right.$ $\mathrm{W} / \mathrm{m} / \mathrm{K})$ than biomass $\left(\sim 85 \times 10^{-3} \mathrm{~W} / \mathrm{m} / \mathrm{K}\right)$. The dependence of biomass thermal conductivity on sample density was also reported by previous research [30]. Moreover, a strong negative correlation between thermal conductivity and particle size was reported by Hankalin et al. [31]. Biomass with smaller particle size has a higher thermal conductivity, which results in a better heat transfer and/or mass transfer in thermal processing. Thus, biomass with small particle size is considered advantageous to thermal conduct efficiency and has a higher production yield in the thermal conversion process [32].

To study the effects of planting location and ecotype on thermal conductivity of big bluestem, the probe method was conducted with the $1-\mathrm{mm}$ sample in $360 \mathrm{~kg} / \mathrm{m}^{3}$ at $298 \mathrm{~K}$. Thermal conductivity values were in the range of $77.85-99.06 \times 10^{-3} \mathrm{~W} / \mathrm{m} / \mathrm{K}$ at room temperature, depending on planting location and ecotype (Table 1). This result was higher than the thermal

conductivity of woody and grass biomass $\left(46.12-76.23 \times 10^{-3} \mathrm{~W} / \mathrm{m} / \mathrm{K}\right)$ reported by Yang et al. 
[27] and is partly explained by the fact that the thermal conductivity was measured on samples with higher sample density in this study. In Figure 5, although there was no significant difference in mean value of thermal conductivity among the planting locations and ecotypes, the thermal conductivity of the Illinois location (average $88.49 \times 10^{-3} \mathrm{~W} / \mathrm{m} / \mathrm{K}$ ) and KAW (average $86.70 \times 10^{-}$

${ }^{3} \mathrm{~W} / \mathrm{m} / \mathrm{K}$ ) was higher than those of the Colby location (average $74.999 \times 10^{-3} \mathrm{~W} / \mathrm{m} / \mathrm{K}$ ) and CKS ecotype (average $78.55 \times 10^{-3} \mathrm{~W} / \mathrm{m} / \mathrm{K}$ ). It is suggested that location and ecotype did not have significant effects on the average thermal conductivity from west to east, probably because thermal conductivity was not affected solely by location and ecotype. Table 5 showed the high correlation $\left(\mathrm{R}^{2}=0.99,0.98\right.$, and 0.95$)$ between potential evapotranspiration, aridity index, precipitation since 1961, and thermal conductivity, indicating that these three environmental factors may play a significant role in thermal conductivity values of big bluestem.

\subsection{Thermogravimetric analysis}

The thermogravimetric data were summarized in Table 1. Figure 6 shows the typical TGA and DTG curves of big bluestem. In general, all big bluestem samples revealed similar curves: samples lost $10 \%$ of their weight within the temperature range of 30 to $250{ }^{\circ} \mathrm{C}$, and significant weight loss occurred between $250{ }^{\circ} \mathrm{C}$ and $400{ }^{\circ} \mathrm{C}$. The weight loss of big bluestems growing in Kansas and those from Illinois were 71 and 73\%, respectively, after achieving thermogram plateaus during heating. This result suggested that big bluestem growing in Illinois contained a higher amount of thermal decomposition contents (cellulose, hemicellulose, and lignin) compared with samples from the Kansas growing locations. The weight loss of big bluestem was significantly affected by both planting location and ecotype (Table 2). This result followed a similar trend in previous chemical composition analysis. In other words, big bluestem from 
Illinois and KAW ecotypes had higher carbohydrate and lignin contents with weight loss than their counterparts.

For DTG profiles, the rate of weight loss versus temperature of big bluestem, all curves exhibited three-stage thermal decomposition behaviors. The first stage occurred at peak temperature around 80 to $85{ }^{\circ} \mathrm{C}$, which was related to the evaporation of water in the samples prior to the bulk of the weight loss. The second peak, decomposition of hemicellulose, was relatively small and located at 195 to $255{ }^{\circ} \mathrm{C}$, which is partly overlapped by the biggest peak. The third stage appeared from 200 to $510{ }^{\circ} \mathrm{C}$, with $65 \%$ weight loss and peak temperature around 355 to $365{ }^{\circ} \mathrm{C}$, indicating thermal decomposition of the main constituents of big bluestem, including cellulose and lignin. Hemicellulose was easy to decompose at a low temperature of 200 to $315{ }^{\circ} \mathrm{C}$ because of its random, amorphous, and rich branch structure [27]. The thermal decomposition of cellulose occurred at temperatures ranging from 275 to $350{ }^{\circ} \mathrm{C}$ [33]. Among the three constituents, lignin was the most difficult to decompose under the whole temperature range from 200 to $600{ }^{\circ} \mathrm{C}$ because its complicated oxygen functional groups have different thermal stabilities [34]. Based on statistical results in Table 2, although no significant difference in averages of $T_{\text {one }}$ and $T_{\text {end }}$ were observed among ecotype and interaction and ecotype, those thermogravimetric parameters of big bluestem were significantly affected by planting location $(p<0.05) . T_{\max }$ was significantly affected by all three factors. These results suggested that planting location rather than ecotype and interaction influenced the thermal stability of big bluestem. Furthermore, the weight loss of big bluestem gradually increased to about $3 \%$ as planting location changed from west to east. This result qualitatively confirms the variation trend of contents of carbohydrates and lignin in previous research [21]. Multiple univariate linear regression analysis was conducted 
to find significant associations of environmental predictors with thermogravimetric parameters, and the results showed $89 \%$ of the variation in the end time of thermal decomposition $\left(T_{\text {end }}\right), 86 \%$ of the variation in the maximum time of thermal decomposition $\left(T_{\max }\right)$, and $71 \%$ of the variation in the weight loss were explained by potential evapotranspiration. Precipitation in 2010 also explained a large variation in the onset time of thermal decomposition $\left(T_{\text {onset }}\right)$ of the big bluestem samples with coefficients of determination $\left(\mathrm{R}^{2}=0.70\right)$ in growing year 2010 (Table 5).

\subsection{High heating value and proximate analysis}

Heating value is the most important parameter in characterizing a substance as combustible, and it is widely used in the determination of a number of additional thermal properties such as enthalpy of formation and adiabatic reaction temperature. High heating value (HHV), representing the heat of combustion relative to liquid water as the product, was measured with an adiabatic oxygen bomb calorimeter and compared with the predicted HHV based on ultimate and proximate analysis methods (Table 4). The proximate and ultimate analyses of biomass are essential for their efficient and clean utilization, whereas the HHV of these materials determine the quantitative energy content of these fuels. The HHV of big bluestem ranged from 17.28 to 19.05 MJ/kg. Prediction model 1 (Dulong-Bertholot equation) overpredicts the HHV of samples and appears to have bigger bias error to experimental value. Nevertheless, the deviation of the prediction model 2 based on simple and rapid proximate analysis falls in a narrower range with the least residual sum of squares (RSS), indicating proximate analysis is good choice in terms of the accuracy of predicting HHV (Table 4). According to the correlations among HHV and proximate analysis components (volatile matter, fixed carbon, and ash) in this study, the resulting equation 5 has been derived from multiple linear regression analysis with factors (volatile matter 
and fixed carbon) using a least squares fitting program. This equation accounted for $85.5 \%$ of variation with a standard error of the estimate of 254.68 :

High heating value $=-1109.78+207.46$ volatile matter +210.82 fixed carbon

In general, higher fixed carbon and volatile matter contents resulted in a higher HHV. Big bluestem from Illinois had significantly higher HHV (average of $18.67 \mathrm{MJ} / \mathrm{kg}$ ) than those from Kansas (average of $17.64 \mathrm{MJ} / \mathrm{kg}$ for Colby, KS; average of $17.73 \mathrm{MJ} / \mathrm{kg}$ for Hays, KS; and average of $18.07 \mathrm{MJ} / \mathrm{kg}$ for Manhattan, KS) (Table 4). In addition to location, the effect of ecotype on HHV showed the same trend as on specific heating of big bluestem. KAW had significantly higher HHV than other ecotypes, which might be partly attributed to the higher carbohydrate contents of native cultivar. In general, HHV of big bluestem was significantly affected by location $(p<0.01)$ and ecotype $(p<0.01)$, with the former being more influential (as shown by a large $F$-value). The interaction effect of ecotype and location on HHV was statistically insignificant $(p>0.05)$.

Table 4 shows the results of the proximate analysis calculated on a dry basis. The volatile matter content of big bluestem ranged from 68.75 to $74.65 \%$. The volatile matter was exclusive of moisture vapor and consists of permanent gases such as $\mathrm{CH}_{4}, \mathrm{CO}_{2}$, and $\mathrm{CO}$ forming the bio-oil after condensation [35]. Fixed carbon, producing a char and burning as a solid material in the combustion system, ranged from 16.75 to $19.24 \%$. Ash, the inorganic residues, ranged from 4.35 to $11.46 \%$. Variations in the fixed carbon, volatile, and ash contents among the 16 samples were analyzed by two-way ANOVA to examine the genetic and environmental effects on proximate analysis of the big bluestem. With the exception of the interaction effect on the fixed carbon, significant effects of planting location, ecotype, and an interaction between location and ecotype were observed on the volatile matter, fixed carbon, and ash contents. Location had larger $F$ 
values (50.16-1426.49) than ecotype (5.51-278.24) and interactions (1.53-85.55), showing that location effects were always highly significant, with much larger $F$ values on proximate analysis of big bluestem, an order of magnitude larger than $F$ values of ecotype and their interaction for volatile matter and fixed carbon contents, and approaching more than three orders of magnitude larger for ash content (Table 5). Table 5 shows environmental factors, including mean annual precipitation since 1961, potential evapotranspiration, and aridity index variation, which had a significant effect on the heat value with large coefficients of determination $\left(R^{2}>0.90\right)$. The mean annual precipitation since 1961 in Illinois is twice as high as that in Colby, which provides a better environment for big bluestem with high heating value. For proximate analysis, variables were also associated with environmental predictors; the potential evapotranspiration explained 64,86 , and $79 \%$ of the variation in volatile matter content, fixed carbon content, and ash content, respectively. It is suggested that the potential evapotranspiration played a greater role in divergence of the high heating value and proximate analysis variables of the big bluestem.

\section{Conclusions}

Specific heat of big bluestem was significantly affected by planting location, ecotype, and interaction between location and ecotype, but location was the dominant factor. A positive correlation model was developed between specific heat and temperature. There was no significant effect on thermal conductivity of big bluestem. A positive relationship between thermal conductivity and density and a negative relationship between the particle size and thermal conductivity were observed. With the exception of weight loss, planting location alone had a significant effect on thermogravimetric parameters of big bluestem. As a general 
conclusion, both planting location and ecotype significantly affected high heating value, but the

former was more influential. Potential evapotranspiration was the most significant environmental

factor affecting all thermal properties of big bluestem selected for this study.

\section{Acknowledgments}

The project was supported by U.S. Department of Transportation Sun Grant Program with

Project No.DTOS59-07-G-00053 and also partly supported by NSF with award No. CMMI-

0970112, United States Department of Agriculture, Abiotic Stress Program [2008-35100-04545],

and the U.S. Department of Agriculture, National Institute of Food and Agriculture (grant no.

2008-35100-04545). Contribution number 12-271-J from the Kansas Agricultural Experiment

Station.

\section{References}

[1] Bioenergy I. The Role of Bioenergy in Greenhouse Gas Mitigation, Position Paper. IEA Bioenergy, New Zealand. 1998.

[2] Yaman S. Pyrolysis of biomass to produce fuels and chemical feedstocks. Energy Conversion and Management. 2004;45(5):651-71.

[3] Propheter JL, Staggenborg S. Performance of annual and perennial biofuel crops: nutrient removal during the first two years. Agronomy Journal. 2010;102(2):798-805.

[4] Lynd LR, Cushman JH, Nichols RJ, Wyman CE. Fuel ethanol from cellulosic biomass. Science(Washington). 1991;251(4999):1318-23.

[5] Weaver JE. Prairie plants and their environment. A fifty-year study in the midwest. Prairie plants and their environment A fifty-year study in the midwest. 1968.

[6] Knapp AK, Briggs JM, Hartnett DC, Collins SL. Grassland dynamics: long-term ecological research in tallgrass prairie: Oxford University Press New York, 1998.

[7] Moser LE, Vogel KP. Switchgrass, big bluestem, and indiangrass. Forages. 1995;1:409-20.

[8] Moore KJ, Anderson BE. Native warm-season grasses: research trends and issues. Proceedings of the Native Warm-Season Grass Conference and Expo, Des Moines, Iowa, USA, 12-13 September, 1996. Conference Native warm-season grasses: research trends and issues. Proceedings of the Native Warm-Season Grass Conference and Expo, Des Moines, Iowa, USA, 12-13 September, 1996. Crop Science Society of America.

[9] Anderson BE. Use of warm-season grasses by grazing livestock. Native warm-season grasses: research trends and issues. 2000 (nativewarmseaso):147-57.

[10] Gelfand I, Sahajpal R, Zhang X, Izaurralde RC, Gross KL, Robertson GP. Sustainable bioenergy production from marginal lands in the US Midwest. Nature. 2013;493(7433):514-7.

[11] Demirbas A. Combustion characteristics of different biomass fuels. Progress in energy and combustion science. 2004;30(2):219-30. 
[12] Czernik S, Bridgwater A. Overview of applications of biomass fast pyrolysis oil. Energy \& Fuels. 2004;18(2):590-8.

[13] Bridgwater A. Renewable fuels and chemicals by thermal processing of biomass. Chemical Engineering Journal. 2003;91(2):87-102.

[14] Shankar Tumuluru J, Sokhansanj S, Hess JR, Wright CT, Boardman RD. REVIEW: A review on biomass torrefaction process and product properties for energy applications. Industrial Biotechnology. 2011;7(5):384-401.

[15] Sweat VE. Thermal properties of foods. FOOD SCIENCE AND TECHNOLOGY-NEW YORK-MARCEL DEKKER-. 1995:99-.

[16] Rahman MS. Food properties handbook: CRC press, 2010.

[17] Koch P. Specific heat of ovendry spruce pine wood and bark. Wood Science. 1969;1(4):203-14.

[18] Monsenin N. Thermal properties of foods and other agricultural materials: CRC Press, 1980.

[19] Murakami E, Sweat V, Sastry S, Kolbe E. Analysis of various design and operating parameters of the thermal conductivity probe. Journal of food engineering. 1996;30(1):209-25.

[20] Dranca I, Vyazovkin S. Thermal stability of gelatin gels: Effect of preparation conditions on the activation energy barrier to melting. Polymer. 2009;50(20):4859-67.

[21] Zhang K, Johnson L, Nelson R, Yuan W, Pei Z, Wang D. Chemical and elemental composition of big bluestem as affected by ecotype and planting location along the precipitation gradient of the Great Plains. Industrial Crops and Products. 2012;40:210-8.

[22] Gan J, Yuan W, Johnson L, Wang D, Nelson R, Zhang K. Hydrothermal conversion of big bluestem for bio-oil production: The effect of ecotype and planting location. Bioresource Technology. 2012;116:413-20.

[23] ASTM. Standard D-1102-84, 1984 (2001) "Stander test method for ash in wood,". West Conshohocken, PA: ASTM International; 2001.

[24] ASTM. Standard E872-82, 1982 (2006) "Standard test method for volatile matter in the analysis of particulate wood fuels," West Conshohocken, PA: ASTM International; 2006.

[25] Wolfinger M, Rath J, Krammer G, Barontini F, Cozzani V. Influence of the emissivity of the sample on differential scanning calorimetry measurements. Thermochimica acta. 2001;372(1):11-8.

[26] Strezov V, Patterson M, Zymla V, Fisher K, Evans TJ, Nelson PF. Fundamental aspects of biomass carbonisation. Journal of analytical and applied pyrolysis. 2007;79(1):91-100.

[27] Yang H, Yan R, Chen H, Lee DH, Zheng C. Characteristics of hemicellulose, cellulose and lignin pyrolysis. Fuel. 2007;86(12):1781-8.

[28] Larfeldt J, Leckner B, Melaaen MC. Modelling and measurements of the pyrolysis of large wood particles. Fuel. 2000;79(13):1637-43.

[29] Gupta M, Yang J, Roy C. Specific heat and thermal conductivity of softwood bark and softwood char particles. Fuel. 2003;82(8):919-27.

[30] Siritheerasas P, Phantachot K, Jatarapornanun V. Determination of Thermal Conductivity of Thai Biomass. Chiangmai, Thailand 17th National Chemical Engineering and Applied Chemistry Conference; 2007.

[31] Hankalin V, Ahonen T, Raiko R. On thermal properties of a pyrolysing wood particle. FinnishSwedish Flame Days. 2009:16.

[32] Li S, Xu S, Liu S, Yang C, Lu Q. Fast pyrolysis of biomass in free-fall reactor for hydrogenrich gas. Fuel Processing Technology. 2004;85(8):1201-11.

[33] Chen W-H, Kuo P-C. A study on torrefaction of various biomass materials and its impact on lignocellulosic structure simulated by a thermogravimetry. Energy. 2010;35(6):2580-6.

[34] Brebu M, Vasile C. Thermal degradation of lignin-A review. Cellulose Chemistry \& Technology. 2010;44(9):353.

[35] Stahl R, Henrich E, Gehrmann H, Vodegel S, Koch M. Definition of a standard biomass. RENEW Project www renew-fuel com/download php. 2004.

[36] Selvig W, Gibson F. Calorific value of coal. Chemistry of coal utilization. 1945;1:139. 
[37] Parikh J, Channiwala S, Ghosal G. A correlation for calculating HHV from proximate analysis of solid fuels. Fuel. 2005;84(5):487-94. 


\section{List of nomenclature}

$C_{p} \quad$ specific heat, $\mathrm{kJ} / \mathrm{kg} / \mathrm{K}$

$C_{p s} \quad$ specific heat of sapphire, $\mathrm{kJ} / \mathrm{kg} / \mathrm{K}$

E specific heat calibration constant

$E_{r e f} \quad$ voltage of the reference resistor, V

$H$ measured heating value, $\mathrm{mW}$

$H_{r} \quad$ heating rate, $\mathrm{K} / \mathrm{min}$

$k$ thermal conductivity, $\mathrm{W} / \mathrm{m} / \mathrm{K}$

M sapphire mass, $\mathrm{mg}$

$q \quad$ heater power dissipated per unit length, $\mathrm{W} / \mathrm{m}$

$R m \quad$ resistance of probe heater, $\Omega$

$R_{r e f} \quad$ resistance of the reference resistor, $\Omega$

$T \quad$ final temperature, $\mathrm{K}$

$t \quad$ final time, s

$T_{0} \quad$ initial temperature, $\mathrm{K}$

$t_{0} \quad$ initial time, $\mathrm{s}$

$T_{\text {end }} \quad$ final temperature of decomposition peak in DTG curve, ${ }^{\circ} \mathrm{C}$

$T_{\max }$ peak temperature of decomposition peak in DTG curve, ${ }^{\circ} \mathrm{C}$

$T_{\text {one }} \quad$ initial temperature of decomposition peak in DTG curve, ${ }^{\circ} \mathrm{C}$ 